\title{
Reversible Insertion of Carbenes into Ruthenium-Silicon Bonds
}

\author{
María J. Bernal, Olga Torres, Marta Martín, ${ }^{*}$ and Eduardo Sola* \\ Instituto de Síntesis Química y Catálisis Homogénea (ISQCH), CSIC-Universidad de Zaragoza, E-50009 Zaragoza, Spain
}

ABSTRACT: The five-coordinate carbene complexes $\left[\mathrm{Ru}\left\{\kappa-P, P, S i-S i(M e)\left(\mathrm{C}_{6} \mathrm{H}_{4}-2-\mathrm{PiPr}_{2}\right)_{2}\right\} \mathrm{Cl}(=\mathrm{CHR})\right](\mathbf{2}, \mathrm{R}=\mathrm{Ph})$ and $(\mathbf{3}, \mathrm{R}=\mathrm{SiMe})$, analogues of Grubbs catalyst, were prepared from the dimer $\left[\mathrm{Ru}(\mu-\mathrm{Cl})\left\{\kappa-P, P, \operatorname{Si}-\mathrm{Si}(\mathrm{Me})\left(\mathrm{C}_{6} \mathrm{H}_{4}-2-\mathrm{PiPr}_{2}\right)_{2}\right\}\right]_{2}(\mathbf{1})$ and the corresponding diazoalkane $\mathrm{N}_{2} \mathrm{CHR}$. The particular structural features that result from the presence of a strongly trans-directing silyl group at the pincer ligand of these complexes are discussed on the basis of NMR information and the crystal structure of the vinylidene analogue $[\mathrm{Ru}\{\kappa-P, P, S i-$ $\left.\left.\mathrm{Si}(\mathrm{Me})\left(\mathrm{C}_{6} \mathrm{H}_{4}-2-\mathrm{PiPr}_{2}\right)_{2}\right\} \mathrm{Cl}(=\mathrm{C}=\mathrm{CHPh})\right](4)$, which was also obtained from $\mathbf{1}$ and phenylacetylene. The reactions of 3 with reagents such as $\mathrm{P}(\mathrm{OMe})_{3}, \mathrm{CO}, \mathrm{NCMe}$ or $\mathrm{K}(\mathrm{acac})$ illustrate that the first response of these carbene complexes to an increase of the coordination number around ruthenium is the insertion of the carbene ligand into the $\mathrm{Ru}-\mathrm{Si}$ bond. These reactions also indicate that the insertion process is reversible and allows typical transformations of carbene ligands such as $\mathrm{C}-\mathrm{H}$ functionalizations via carbene insertion (in the acac ligand) or the formation of ketene from CO. In addition, the reactions of 3 with terminal alkynes such as phenylacetylene or 3,3-dimethyl-1-buthyne show that the inserted carbenes can also undergo reactions typical of metal-bound alkyls such as alkyne insertion or C-H reductive elimination.

\section{INTRODUCTION}

As our mechanistic understanding of coordination and organometallic chemistry increases, we are able to recognize more reactions in which the ligands play a role beyond the mere stereoelectronic influence. Thus, it is increasingly common to find in the chemical literature labels such as "non-innocent", " "cooperating"2 or bifunctional, ${ }^{3}$ to highlight certain properties of some ligands that render them particularly suitable or even essential for transformations occurring at the coordination sphere of metal complexes. Sometimes, the origin of such ligand contributions is an electronic reorganization: a valence tautomerism or resonance. ${ }^{1,4}$ In other cases it is a reversible bond cleavage or formation that happens in the presence of reagents. ${ }^{2,3,5,6}$ Several biochemically relevant systems exploit examples of the first type, ${ }^{7}$ while the latter is at the heart of highly efficient catalytic cycles ${ }^{8}$ and valuable stoichiometric reaction sequences. ${ }^{9}$ This work features a recourse of the latter type for pincer ligands that contain a silyl donor group $(\kappa-P, P, S i)$, which consists of a reversible insertion of carbenes into the metal-silicon bond.

Our interest in this type of pincers was originally due to their capability of controlling the coordination geometry of unsaturated metal complexes via the large trans influence of the silyl group. ${ }^{10,11}$ We intended to exploit this property to shape analogues of the Grubbs catalyst with the vacant coordination site cis to the carbene ligand. ${ }^{12}$ In our hypothesis, such five-coordinate ruthenium complexes could work as olefin metathesis catalysts without the need for pre-activating via ligand dissociation, ${ }^{13}$ thus potentially leading to more robust, compatible and reusable catalysts. The following pages show that, even though the target non-isostructural analogues of Grubbs catalyst are readily accessible, their behavior is dominated by the title reaction and do not work as olefin metathesis catalysts.

RESULTS AND DISCUSSION
Grubbs catalyst analogues based on a $\kappa-P, P, S i$ pincer. The dimer $\left[\mathrm{Ru}(\mu-\mathrm{Cl})\left\{\kappa-P, P, \mathrm{Si}-\mathrm{Si}(\mathrm{Me})\left(\mathrm{C}_{6} \mathrm{H}_{4}-2-\mathrm{PiPr}_{2}\right)_{2}\right\}\right]_{2}$ (1) turned to be a suitable precursor for the preparation of carbene complexes. It was obtained from the reaction of $\left[\mathrm{Ru}(\mu-\mathrm{Cl})_{2}(\operatorname{cod})\right]_{\mathrm{n}}$ with the silane $\mathrm{HSi}(\mathrm{Me})\left(\mathrm{C}_{6} \mathrm{H}_{4}-2-\mathrm{P}_{2} \mathrm{Pr}_{2}\right)_{2}$ in the presence of triethylamine. The structure of $\mathbf{1}$ determined by X-ray crystallography, virtually $C_{2}$ symmetric (Figure 1), is similar to that reported by Tobish, Turculet et al. for the analogous complex with cyclohexyl instead of isopropyl groups. ${ }^{14}$ Also similarly to this precedent, the NMR spectra of $\mathbf{1}$ in solution at room temperature (RT) indicate an averaged higher symmetry, by showing, for example, a single broad resonance in the ${ }^{31} \mathrm{P}\left\{{ }^{1} \mathrm{H}\right\}$ spectrum corresponding to the four phosphorous atoms.

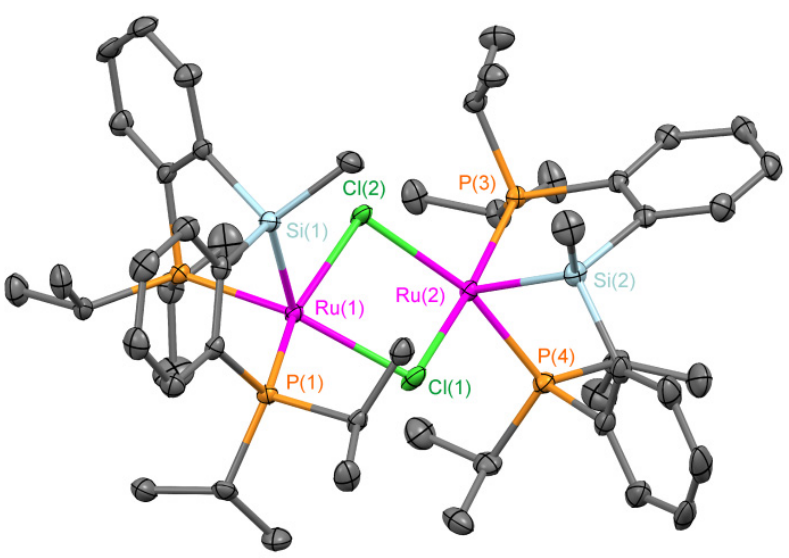

Figure 1. Crystal structure of complex 1 at 50\% probability level. The hydrogen atoms are omitted for clarity. For bond distances and angles see Supporting Information.

Compound 1 was found to react with diazoalkanes such as phenyldiazomethane or trimethylsilyldiazomethane releasing $\mathrm{N}_{2}$ and forming the carbene complexes $\left[\mathrm{Ru}\left\{\kappa-P, P, \mathrm{Si}-\mathrm{Si}(\mathrm{Me})\left(\mathrm{C}_{6} \mathrm{H}_{4}-2-\right.\right.\right.$ $\left.\left.\left.\mathrm{PiPr}_{2}\right)_{2}\right\} \mathrm{Cl}(=\mathrm{CHR})\right](\mathbf{2}, \mathrm{R}=\mathrm{Ph})$ and $\left(\mathbf{3}, \mathrm{R}=\mathrm{SiMe}_{3}\right)$, respectively 
(Scheme 1). The commercial ethyldiazoacetate, however, did not react cleanly under the same conditions, thus showing that this synthetic method is not applicable to any diazoalkane reagent. Actually, only the formation of $\mathbf{3}$ seems to be clean and selective, as the reaction leading to compound $\mathbf{2}$ always gave rise to variable amounts of by-products still unidentified.

\section{Scheme 1}
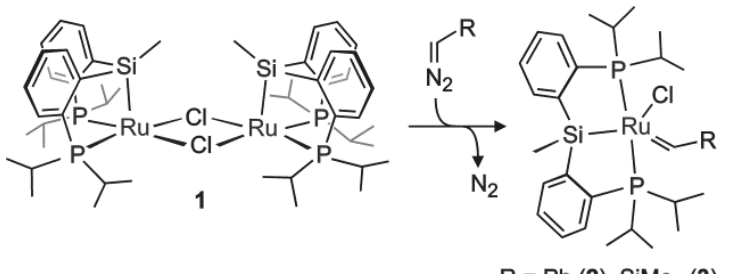

$$
\mathrm{R}=\mathrm{Ph}(2), \mathrm{SiMe}_{3}(\mathbf{3})
$$

The complexes 2 and $\mathbf{3}$ show NMR spectra consistent with equivalent and mutually trans $\mathrm{P} \mathrm{Pr}_{2}$ groups, indicating a change of the coordination mode of the $\kappa-P, P, S i$ ligand from $f a c$ (in $\mathbf{1}$ ) to mer. Accordingly, the carbene ligands' $\mathrm{CHs}$ give rise to characteristic triplet signals in both the ${ }^{1} \mathrm{H}$ and ${ }^{13} \mathrm{C}\left\{{ }^{1} \mathrm{H}\right\}$ NMR spectra: at $\delta 12.51$ $\left(J_{\mathrm{HP}}=6.2\right)$ and $264.69\left(J_{\mathrm{CP}}=3.1\right)$ respectively for 2 , and at $\delta 12.44$ $\left(J_{\mathrm{HP}}=1.8\right)$ and $274.95\left(J_{\mathrm{CP}}=4.9\right)$ for 3 .

Although, so far, we have not been able to grow good crystals for any of these carbene complexes, their likely structural features can be discussed on the $\mathrm{X}$-ray diffraction structure of the analogous vinylidene compound $\quad\left[\mathrm{Ru}\left\{\kappa-P, P, \mathrm{Si}-\mathrm{Si}(\mathrm{Me})\left(\mathrm{C}_{6} \mathrm{H}_{4}-2\right.\right.\right.$ $\left.\left.\left.\mathrm{PiPr}_{2}\right)_{2}\right\} \mathrm{Cl}(=\mathrm{C}=\mathrm{CHPh})\right]$ (4, Figure 2). This derivative was also prepared from precursor $\mathbf{1}$ by reaction with phenylacetylene at RT. The synthesis required several equivalents of the alkyne reagent, as 4 was formed together with the product of phenylacetylene dimerization (Z)-1,4-diphenyl-1-buten-3-yne. Similar selective dimerization processes have already been observed for the parent vinylidene complexes $\left[\mathrm{RuCl}_{2}(=\mathrm{C}=\mathrm{CHPh})\left(\mathrm{PR}_{3}\right)_{2}\right](\mathrm{R}=i \mathrm{Pr}, \mathrm{Cy})$ as catalysts. ${ }^{15}$

\section{Scheme 2}

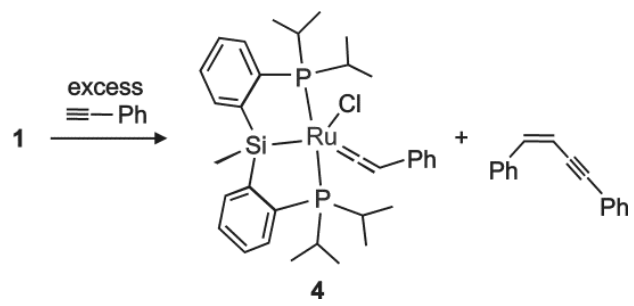

The Figure 2 details the angles in the equatorial plane of the fivecoordinate complex 4 to stress the differences with those found in the abovementioned vinylidene analogues of the Grubbs catalyst $\left[\mathrm{RuCl}_{2}(=\mathrm{C}=\mathrm{CHPh})\left(\mathrm{PR}_{3}\right)_{2}\right]$. In the latter, the vacant coordination site clearly sits trans to the strongly $\sigma$-donor vinylidene ligand, with angles between the chlorides of $161^{\circ}(\mathrm{R}=i \mathrm{Pr}),{ }^{16}$ or $158^{\circ}(\mathrm{R}=$ Cy). ${ }^{16,17}$ In contrast, the silyl function of the $\kappa-P, P, S i$ pincer of 4 seems capable of opening the angle in trans up to $144^{\circ}$ even in the presence of the vinylidene, whose trans angle closes to $131^{\circ}$. In favor of attributing these differences mainly to a competition among the trans influences of the equatorial ligands, the related derivative $\left[\mathrm{RuCl}(\mathrm{NO})(=\mathrm{C}=\mathrm{CHPh})\left(\mathrm{PPh}_{3}\right)_{2}\right]$ also shows the widest angle $\left(139^{\circ}\right)$ trans to the trans-directing bent nitrosyl ligand, ${ }^{18}$ while that trans to vinylidene is just of $113^{\circ} .{ }^{19}$

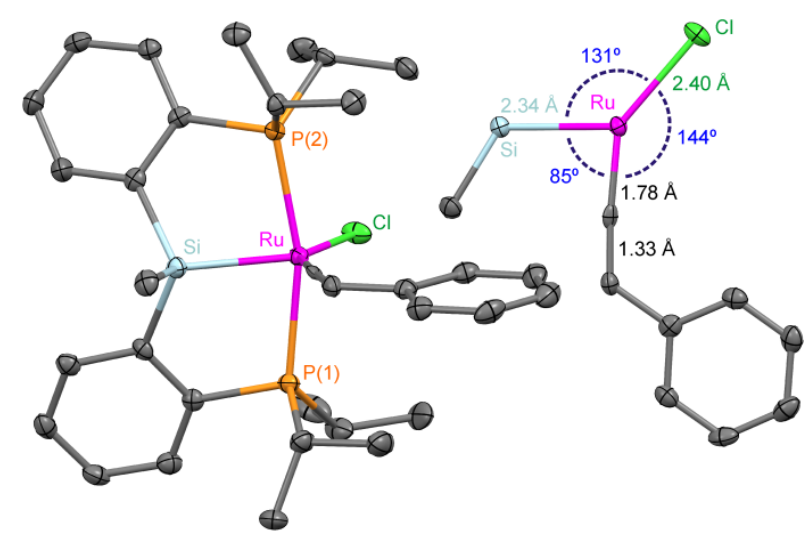

Figure 2. (left) Crystal structure of 4 (50\% probability level) and (right) structural details of the equatorial plane of the complex. The hydrogen atoms are omitted for clarity. For other bond distances and angles see Supporting Information.

Among the various possible isomers for the products of the above reactions, the one represented in Schemes 1 and 2 is the major (2 and $\mathbf{3}$ ) or the only detectable by NMR (4). In this isomer, the carbene or vinylidene ligand occupies the (less hindered) coordination position syn to the methyl at silicon, while the substituent at the carbene or vinylidene avoids the vicinity of this methyl. This is inferred, for all complexes, from the observation of nOe between the ${ }^{1} \mathrm{H}$ NMR signals corresponding to the SiMe and the carbene or vinylidene hydrogen, and is confirmed by the crystal structure of 4 . Such a product selectivity suggests that the $\kappa-P, P, S i$ pincer provides by itself a congested coordination environment. Furthermore, other NMR parameters suggest that the pincer can adapt its coordination angles to accommodate bulky equatorial ligands. This is illustrated in Figure 3 by means of two of the ${ }^{13} \mathrm{C}\left\{{ }^{1} \mathrm{H}\right\}$ NMR signals that are sensitive to the magnitude of the $J_{\mathrm{PP}}$ coupling constant, because correspond to carbons of the pincer backbone for which the two chemically equivalent ${ }^{31} \mathrm{P}$ nuclei are magnetically inequivalent. The signals of complex 4, whose crystal structure indicates a $\mathrm{P}-\mathrm{Ru}-\mathrm{P}$ angle of $165^{\circ}$, are virtual triplets characteristic of strongly coupled phosphorous. This is also the case for the phenyl-substituted carbene $\mathbf{2}$, but not for the trimethylsilyl-substituted derivative 3, whose signals show features halfway between the virtual triplet and those typical of weakly coupled phosphorous. The latter are exemplified in the figure by the signals of complex $\mathbf{1}$, the structure of which shows $\mathrm{P}-\mathrm{Ru}-\mathrm{P}$ angles of 95 and $105^{\circ}$, and whose $303 \mathrm{~K} \mathrm{NMR}$ spectrum indicates an averaged $J_{\mathrm{PP}^{\prime}}$ coupling constant of about $20 \mathrm{~Hz}$. Even though the signal to noise ratio of the ${ }^{13} \mathrm{C}\left\{{ }^{1} \mathrm{H}\right\}$ NMR spectrum of 3 does not allow observation of those side lines of the AXX' spin system that make possible the evaluation of the $J_{\mathrm{PP}}$ constant, the shape of these signals can be considered diagnostic of a distortion of the mer pincer towards a fac coordination. 


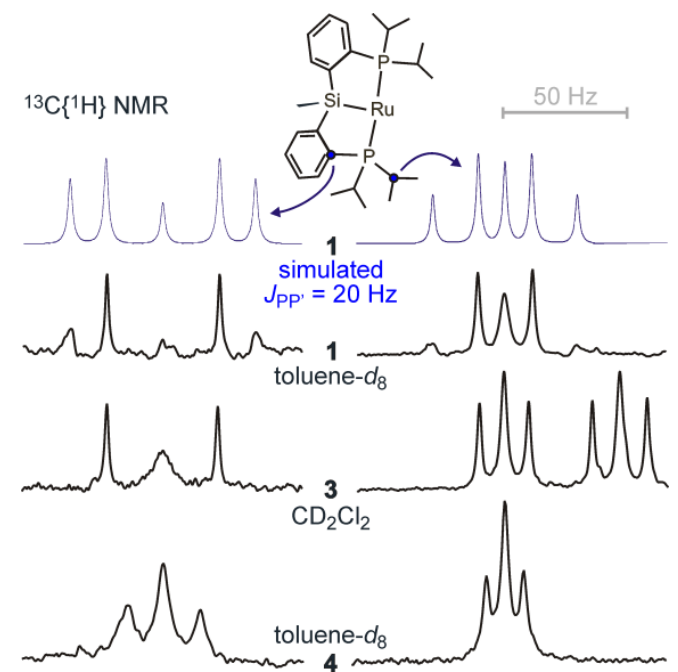

Figure 3. Examples of ${ }^{13} \mathrm{C}\left\{{ }^{1} \mathrm{H}\right\}$ NMR signals corresponding to A nuclei in AXX' spin systems $\left(X={ }^{31} \mathrm{P}\right)$, for complexes $\mathbf{1}, \mathbf{3}$ and $\mathbf{4}$.

Carbene insertion. The possible catalytic activity of the unsaturated carbene complexes $\mathbf{2}$ and $\mathbf{3}$ in olefin metathesis was investigated through reactions and protocols previously proposed in the literature as a standard system of characterization. ${ }^{20}$ None of these experiments gave positive results. The only noticeable observation was the slow isomerization of substrates such as 1,5-cyclooctadiene, diethyldiallyl malonate, allylbenzene or cis-1,4-diacetoxy-2-butene, which was not further investigated. The in situ NMR examination of reactions with ethylene excess did not produce noticeable observations either. However, in contrast to the inertness suggested by these initial experiments, many reagents other than olefins were observed to react with these five-coordinate complexes. The three selected reactions of complex 3 depicted in Scheme 3 support the description and discussion of the elementary process that was repeatedly observed upon ligand or reagent coordination: the insertion of the carbene ligand into the $\mathrm{Ru}-\mathrm{Si}$ bond.

After addition of one equiv. of trimethyphosphite, the solutions of 3 in acetone- $d_{6}$ showed broadened RT ${ }^{1} \mathrm{H}$ and ${ }^{31} \mathrm{P}\left\{{ }^{1} \mathrm{H}\right\}$ NMR spectra (Figure 4). The spectra at low temperature revealed the formation of two new products which, according to their sets of $J_{\mathrm{PP}}$ coupling constants (major product: 416.9, 78.3 and $17.3 \mathrm{~Hz}$; minor product: $236.4,42.3$ and $26.3 \mathrm{~Hz}$ ), show mer arrangements of three inequivalent phosphorous atoms. In view of the typical values for ${ }^{31} \mathrm{P}$ chemical shifts, the major product should have two mutually cis $\mathrm{PiPr}_{2}$ groups, while in the minor these groups seem to be trans. The major product could be identified from its NMR signals as complex 5 (Scheme 3) although, due to the weakness of the ${ }^{1} \mathrm{H}$ NMR nOe effects at the low temperatures required to observe narrow spectra, some details of its stereochemistry remain unknown. Notably, its ${ }^{13} \mathrm{C}\left\{{ }^{1} \mathrm{H}\right\}$ NMR spectrum at $193 \mathrm{~K}$ does not show any signal attributable to a carbene ligand. Instead, an apparent quartet at very high field $(\delta-42.60, \mathrm{CH})$ with $J_{\mathrm{CP}}$ coupling constants of about 8 $\mathrm{Hz}$, can be attributed to a new $\mathrm{Ru}$-alkyl moiety cis to three phosphorous. A second significant change in the NMR spectra upon reaction is the pronounced shift of the ${ }^{29} \mathrm{Si}\left\{{ }^{1} \mathrm{H}\right\}$ signal corresponding to the silicon of the pincer (Figure 5), which moves from $\delta$ $50.72\left(\mathrm{t}, J_{\mathrm{SiP}}=11.7 \mathrm{~Hz}\right)$ to $\delta-9.76\left(\mathrm{dd}, J_{\mathrm{SiP}}=21.1\right.$ and $\left.6.8 \mathrm{~Hz}\right)$. A common explanation for these two NMR features would imply an insertion of the carbene ligand into the $\mathrm{Ru}-\mathrm{Si}$ bond. Such a process generates a chiral centre and therefore inequivalent pincer phosphorous whatever the ligand arrangement. Taking this into account and in view of the ${ }^{29} \mathrm{Si}\left\{{ }^{1} \mathrm{H}\right\}$ NMR signals observed for the minor product of this reaction (Figure 5), this second complex should also contain a $\kappa-C, P, P$ pincer generated via carbene insertion, but coordinated in a mer fashion. Furthermore, the VT evolution of the NMR spectra ( ${ }^{31} \mathrm{P}$ in Figure 4) suggests that the spectral broadening can be attributed to the exchange between both isomers of 5 in equilibrium.

Scheme 3
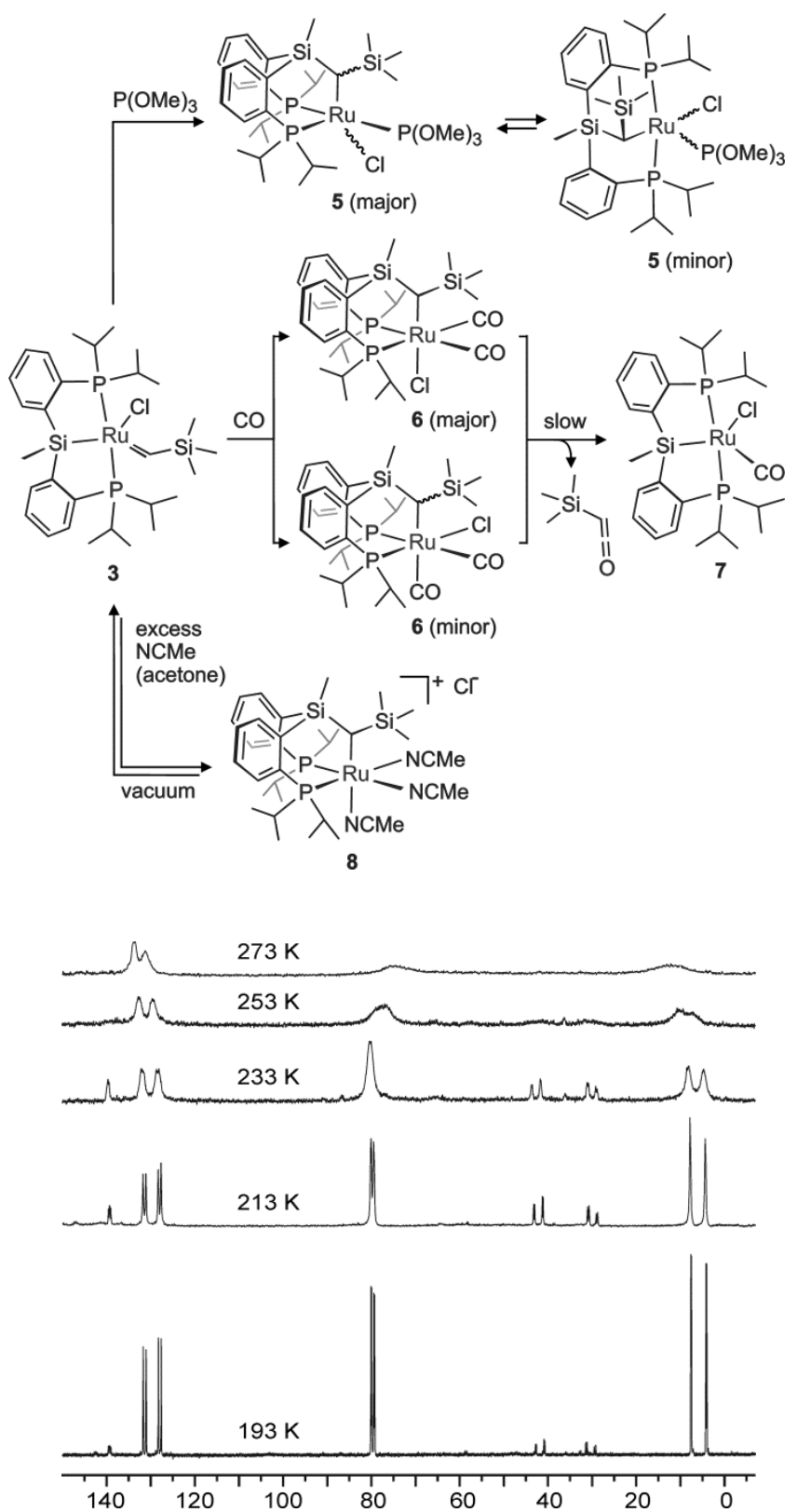

Figure 4. ${ }^{31} \mathrm{P}\left\{{ }^{1} \mathrm{H}\right\}$ NMR spectra of the reaction of $\mathbf{3}$ with one equiv. of $\mathrm{P}(\mathrm{OMe})_{3}$ in acetone- $d_{6}$ at various temperatures.

The second example in Scheme 3, the reaction of 3 with $\mathrm{CO}$, was monitored by $\mathrm{NMR}$ in $\mathrm{CD}_{2} \mathrm{Cl}_{2}$ solution. After bubbling of $\mathrm{CO}$ and subsequent removal of the $\mathrm{CO}$ excess bubbling argon, a mixture of two new complexes was again observed. The NMR spectra of both 
products display the aforementioned features diagnostic of the carbene insertion: inequivalent phosphorous, negative chemical shifts for the ${ }^{29} \mathrm{Si}\left\{{ }^{1} \mathrm{H}\right\}$ NMR signals of the pincer and high field $\mathrm{CH}$ multiplets in the ${ }^{13} \mathrm{C}\left\{{ }^{1} \mathrm{H}\right\}$ NMR spectrum (apparent triplets in this case). The major product (ca. 90\%), complex 6 in Scheme 3, shows two $\mathrm{CO}{ }^{13} \mathrm{C}\left\{{ }^{1} \mathrm{H}\right\}$ NMR signals indicative of ligands trans to phosphorous: doublets of doublets at $\delta 199.02$ and 198.09 with $J_{\mathrm{CP}}$ coupling constants of 77.2, $17.2 \mathrm{~Hz}$ and $74.7,20.2 \mathrm{~Hz}$, respectively. Also in view of its $\mathrm{CO}{ }^{13} \mathrm{C}\left\{{ }^{1} \mathrm{H}\right\}$ NMR signals, the minor product of this reaction should be an isomer of $\mathbf{6}$ with the chloride trans to phosphorous, although the spectra do not allow to distinguish between the two possible.

3, $293 \mathrm{~K}$
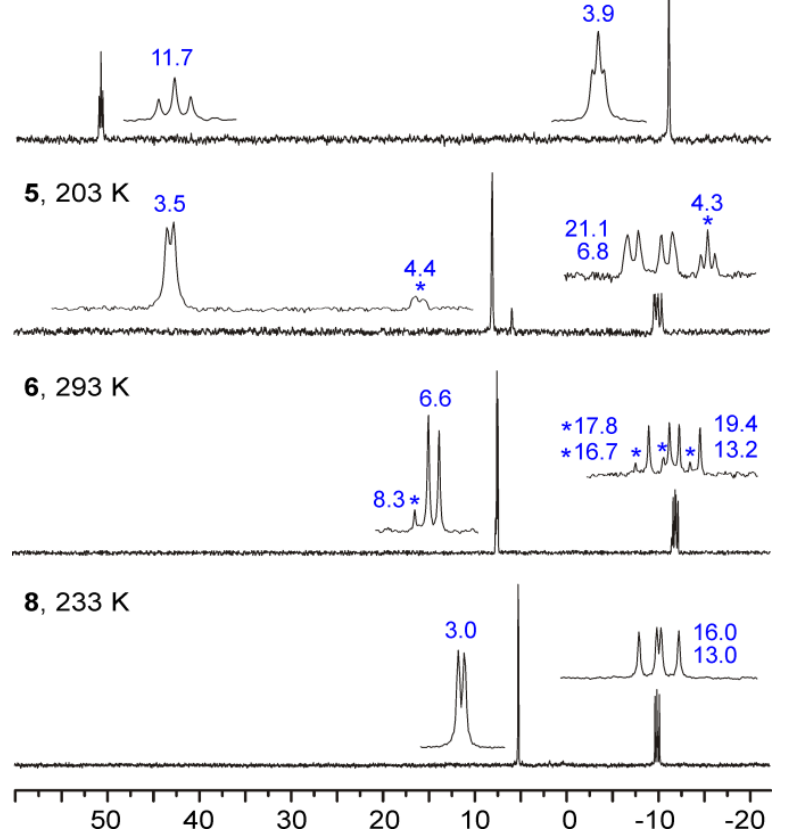

Figure 5. ${ }^{29} \mathrm{Si}\left\{{ }^{1} \mathrm{H}\right\} \mathrm{NMR}$ spectra of $\mathbf{3}$ and the products of its reactions with $\mathrm{P}(\mathrm{OMe})_{3}(\mathbf{5}), \mathrm{CO}$ excess $(\mathbf{6})$ and $\mathrm{NCMe}$ excess $(\mathbf{8})$. In blue $J_{\mathrm{SiP}}$ coupling constants. Asterisks denote signals and constants corresponding to the minor products.

Complex 6 was found to slowly transform (days at RT) into the five-coordinate complex $\left[\mathrm{Ru}\left\{\kappa-P, P, \mathrm{Si}-\mathrm{Si}(\mathrm{Me})\left(\mathrm{C}_{6} \mathrm{H}_{4}-2-\mathrm{PiPr}_{2}\right)_{2}\right\} \mathrm{Cl}\right.$ $(\mathrm{CO})](7)$ and trimethylsilylketene. The latter was identified in the reaction mixture by means of its reported ${ }^{1} \mathrm{H},{ }^{13} \mathrm{C}\left\{{ }^{1} \mathrm{H}\right\}$ and ${ }^{29} \mathrm{Si}\left\{{ }^{1} \mathrm{H}\right\}$ NMR signals. ${ }^{21}$ This reactive compound was formed just as a transient species, disappearing to give products that could not be identified. Complex 7 was formed as a single isomer displaying a syn relative orientation of the CO ligand and the methyl at silicon. This compound could also be prepared by alternative methods such as the reaction of precursor $\left[\mathrm{RuHCl}(\mathrm{CO})\left(\mathrm{PPh}_{3}\right)_{3}\right]$ with the silane $\mathrm{HSi}(\mathrm{Me})\left(\mathrm{C}_{6} \mathrm{H}_{4}-2-\mathrm{PiPr}_{2}\right)_{2}$ or, more simply, by addition of a drop of ethanol during the synthesis of $\mathbf{1}$. The crystal structure of $\mathbf{7}$ can be found in the Supporting Information. Its most noticeable feature is an angle trans to silicon of $178^{\circ}$, which supports the structural arguments based on trans influences given in the previous section. The possible reaction of 7 with trimethylsilyldiazomethane was investigated because it could enable a catalytic synthesis of the ketene. ${ }^{22}$ However, the only new products detected by NMR in this reaction were those of carbene dimerization.
The observed evolution of $\mathbf{6}$ strongly suggests that the process of carbene insertion into the $\mathrm{Ru}-\mathrm{Si}$ bond is reversible. A much clearer evidence of that was obtained from the last reaction of Scheme 3, in which the acetonitrile provoked not only the carbene insertion but also the displacement of the chloride outside the coordination sphere of the metal. The single product of this reaction, the cationic complex 8, showed broadened NMR spectra above $240 \mathrm{~K}$ due to the facile acetonitrile dissociations. At low temperature, the ${ }^{1} \mathrm{H}$, ${ }^{13} \mathrm{C}\left\{{ }^{1} \mathrm{H}\right\}$ and ${ }^{29} \mathrm{Si}\left\{{ }^{1} \mathrm{H}\right\}$ (Figure 5) NMR spectra were fully consistent with the proposed structure. Noteworthy, when the solutions of $\mathbf{8}$ were dried in vacuo and the residue re-dissolved, the NMR spectra indicated the quantitative regeneration of the carbene precursor 3. In fact, this represented a difficulty to isolate $\mathbf{8}$ as a pure solid, which was overcome by removing the chloride from the solution with silver triflate, thus isolating $\mathbf{8}$ as its triflate salt.

Although insertion reactions of metal-bound carbenes are relatively common, ${ }^{23,24}$ the reactions of Scheme 3 represent, to the best of our knowledge, the first examples of such an insertion into a metal-silicon bond. Furthermore, reversible migratory insertions of carbenes such as these are rare. ${ }^{25,26}$ Perhaps, the closest precedent for this reaction can be found in the treatment of the iridium(I) complex $\left[\operatorname{Ir}\left\{\kappa-N, P, P-\mathrm{N}\left(\mathrm{C}_{6} \mathrm{H}_{3}-4-\mathrm{Me}-2-\mathrm{PiPr}_{2}\right)_{2}\right\}(=\mathrm{CHO} t \mathrm{Bu})\right]$ with excess $\mathrm{CO}$, which causes the migratory insertion of the alkoxycarbene into the $\mathrm{Ir}-\mathrm{N}$ bond of the amidophosphine pincer. ${ }^{26}$ Such a process was also proposed to be reversible on the basis of the product thermal evolution, which resembles that of $\mathbf{6}$. On the other hand, the involvement of the silicon atom of $\kappa-P, P, S i$ pincers in processes of bond cleavage and formation has been frequently observed; $;^{27-29}$ a fact suggesting that such pincers are less inert than their $\kappa-C, P, P$ or $\kappa-N, P, P$ counterparts. ${ }^{30}$ In particular, oxo groups and hydroxo ligands have been reported to insert, respectively, into $\mathrm{Ru}-\mathrm{Si}^{29}$ and $\mathrm{Ir}-\mathrm{Si}^{28}$ bonds of complexes with $\kappa-P, P, S i$ pincers. Moreover, the reversible formation of a $\mathrm{Si}-\mathrm{C}$ bond by reductive elimination might be involved in the unusual hydrocarboxylation of allenes with $\mathrm{CO}_{2}$ catalyzed by a palladium $\kappa-P, P, S i$ complex. ${ }^{31}$

$\mathrm{X}$-ray diffraction confirmation of the carbene migratory insertion and further evidence of its reversibility were obtained from the reaction sequence of Scheme 4: initiated by a substitution of the chloride ligand by acetylacetonate (acac). As in the previous examples, this reaction was expected to increase the coordination number of the complex, thus triggering carbene migration.

\section{Scheme 4}

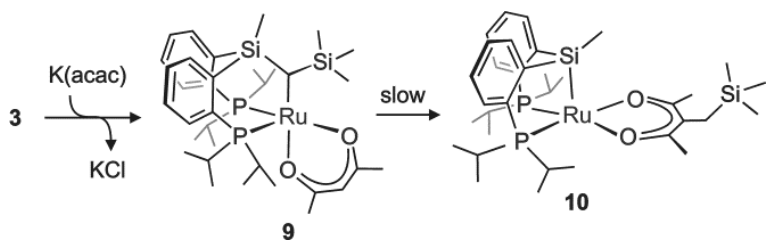

The structure of the expected reaction product, complex 9, is shown in Figure 6. It can be described as square-pyramidal, with the vacant site trans to one of the phosphorous of the new fac $\kappa$ $\mathrm{C}, P, P$ pincer generated after carbene insertion ( $\mathrm{P}-\mathrm{Ru}-\mathrm{P}$ angle $104^{\circ}$ ). Although, just considering trans influences, this is not the most likely ligand arrangement, it seems to be the one sterically favored as it gives more space to accommodate the bulky $\mathrm{SiMe}_{3}$ group. In any case, the trans influences of the alkyl and phospho- 
rous arms of the pincer are not that different, as inferred from the two $\mathrm{Ru}-\mathrm{O}$ distances of the acac ligand: 2.1385 (13) $\AA$ trans to $\mathrm{C}$ and 2.0960(13) $\AA$ trans to P. In line with these considerations, it should be mentioned that the RT NMR spectra of 9 are inconsistent with the solid state structure, since both the ${ }^{1} \mathrm{H}$ and ${ }^{13} \mathrm{C}\left\{{ }^{1} \mathrm{H}\right\}$ NMR signals corresponding to the acac indicate a symmetry element that relates both halves of the ligand. The spectra at low temperature, however, show the decoalescence of each NMR signal into two of approximate relative integral 3:1 (in toluene- $d_{8}$ ). Then, the structure of 9 shown in Figure 6 should be in equilibrium with a second coordination isomer of similar energy, whose fast exchange in the NMR time scale with 9 averages the acac signals but not those of the $\kappa-C, P, P$ pincer.

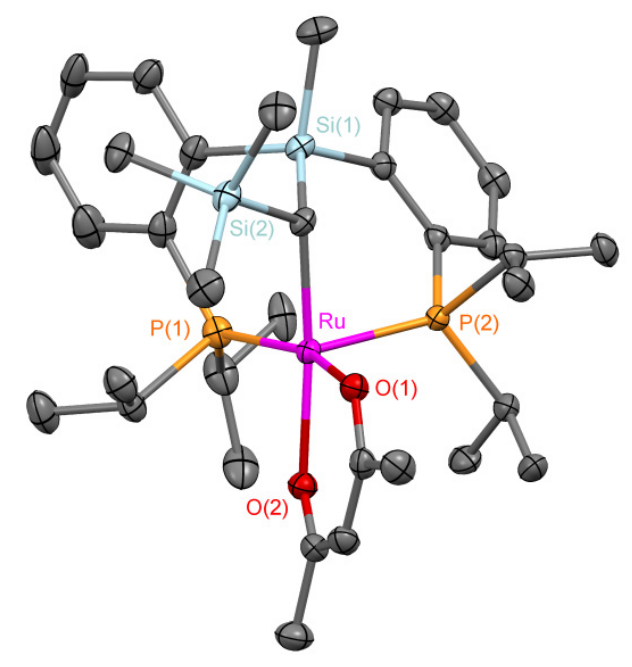

Figure 6. Crystal structure of complex 9 at 50\% probability level. The hydrogen atoms are omitted for clarity. For bond distances and angles see Supporting Information.

Complex 9 was observed to evolve in solution into a new product, 10. The reaction took several days at RT but just few hours in toluene at $363 \mathrm{~K}$. The NMR spectra of $\mathbf{1 0}$ indicate a symmetric structure with equivalent ${ }^{31} \mathrm{P}$ nuclei: a feature by itself demonstrative of the reversal of the carbene insertion. Consistently, the ${ }^{29} \mathrm{Si}\left\{{ }^{1} \mathrm{H}\right\}$ NMR spectrum of the compound recovers the low field signal characteristic of the pincer's $\kappa-P, P, S i$ coordination: in this case a triplet at $\delta 69.37$ with a $J_{\text {SiP }}$ coupling constant of $19.0 \mathrm{~Hz}$. The NMR spectra also confirms that the $\mathrm{SiMe}_{3}$ group remains at the complex, although the ${ }^{13} \mathrm{C}\left\{{ }^{1} \mathrm{H}\right\}$ NMR spectrum does not show any $\mathrm{CH}$ signal attributable to a Ru-bound alkyl or carbene ligand. Instead, the disappearing of the acac $\mathrm{CH}$ and the presence of a new methylene group is evident from the ${ }^{1} \mathrm{H}$ and ${ }^{13} \mathrm{C}\left\{{ }^{1} \mathrm{H}\right\}$ NMR spectra and their correlation experiments. All these NMR features point to the structure of $\mathbf{1 0}$ shown in Scheme 4. This proposal is further supported by the similitude between the NMR spectra of $\mathbf{1 0}$ and those recorded for the closely related complex $[\mathrm{Ru}\{\kappa-P, P, S i$ $\left.\left.\mathrm{Si}(\mathrm{Me})\left(\mathrm{C}_{6} \mathrm{H}_{4}-2-\mathrm{Pi}_{2}\right)_{2}\right\}(\mathrm{acac})\right]$ (11), which was prepared for this purpose from 1 and $\mathrm{K}(\mathrm{acac})$. The similarities between 10 and 11 include the shape of the ${ }^{13} \mathrm{C}\left\{{ }^{1} \mathrm{H}\right\}$ NMR signals of the pincer backbone that are sensitive to the magnitude of the $J_{\mathrm{PP}}$ coupling constant (see Figure 3 and accompanying discussion), which are also similar to those of $\mathbf{1}$, thereby indicating a fac coordination mode of the pincer.
Together, Schemes 1 and 4 compose a reaction sequence for acac functionalization via insertion of the carbene into a $\mathrm{C}-\mathrm{H}$ bond. ${ }^{32}$ These type of functionalization is known to be catalyzed by a variety of transition metal complexes, especially of rhodium and coinage metals. ${ }^{33}$ Ruthenium carbenes, however, are thought to be too unreactive for such funcionalizations, as only few exceptional examples of intramolecular reactions have been reported. ${ }^{34}$ In the present case, the carbene insertion into the $\mathrm{Ru}-\mathrm{Si}$ bond should certainly contribute to accommodate the anionic substrate in the coordination sphere of ruthenium, and might be behind the success of the process.

Further transformations of the inserted carbene. None of the aforementioned complexes featuring inserted carbenes was found to be stable in solution for long periods although, with the exception of $\mathbf{6}$ and 9, their evolutions turned out to be too unselective and could not be understood. Yet, the acac functionalization leading to $\mathbf{1 0}$ (Scheme 4) and the release of ketene from $\mathbf{6}$ (Scheme 3) demonstrate that the "masked carbenes" of these complexes remain useful for new bond formations via migratory deinsertion from the silyl-substituted metal alkyls. Nevertheless, carbene deinsertion is not the only option for these alkyls, as inferred from the two reactions between 3 and terminal alkynes shown in Scheme 5 .

\section{Scheme 5}

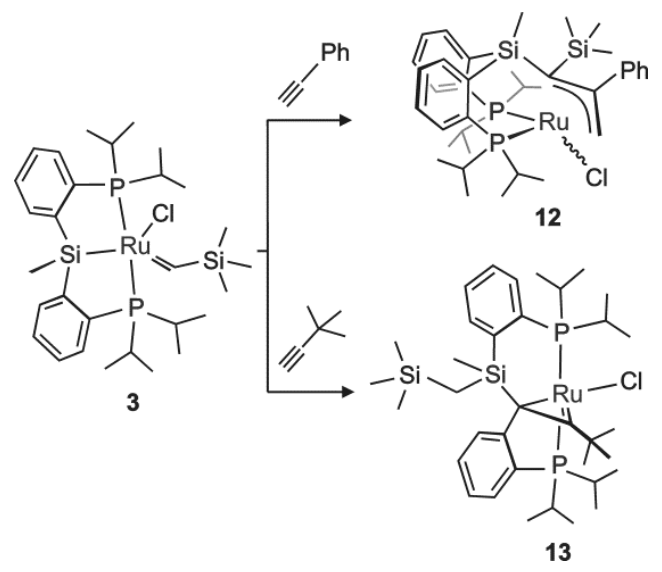

The reaction of $\mathbf{3}$ with phenylacetylene at RT completed in few minutes giving complex $\mathbf{1 2}$ together with traces of the alkyne dimerization product (Z)-1,4-diphenyl-1-buten-3-yne. The ${ }^{1} \mathrm{H}$, ${ }^{13} \mathrm{C}\left\{{ }^{1} \mathrm{H}\right\}$ and ${ }^{29} \mathrm{Si}\left\{{ }^{1} \mathrm{H}\right\}$ NMR spectra of $\mathbf{1 2}$ display many similarities with those of the carbene insertion products described above, although the characteristic ${ }^{13} \mathrm{C}\left\{{ }^{1} \mathrm{H}\right\}$ NMR high field signal corresponding to the $\mathrm{Ru}$-bound carbon is now a $\mathrm{CH}_{2}$ instead of a $\mathrm{CH}$ (a doublet at $\delta-19.59$ with a $J_{\mathrm{CP}}$ coupling constant of $6.8 \mathrm{~Hz}$ ). This signal correlates in the ${ }^{1} \mathrm{H},{ }^{13} \mathrm{C}$ hsqc NMR spectrum with those of two inequivalent hydrogens: a doublet at $\delta-0.02$ showing a $J_{\mathrm{HH}}$ coupling constant of $9.0 \mathrm{~Hz}$, and a multiplet at $\delta-0.34$ which additionally shows two $J_{\mathrm{HP}}$ coupling constants of 11.5 and $2.7 \mathrm{~Hz}$. Beside the signals from carbons of the former $\kappa-P, P, S i$ ligand skeleton and a phenyl ring (broad), the ${ }^{13} \mathrm{C}\left\{{ }^{1} \mathrm{H}\right\}$ NMR spectrum shows two resonances corresponding to quaternary carbons at $\delta 185.13$ (dd, $J_{\mathrm{CP}}=17.6$ and $\left.6.7 \mathrm{~Hz}\right)$ and $151.46\left(\mathrm{dd}\right.$, both $\left.J_{\mathrm{CP}}=1.8 \mathrm{~Hz}\right)$. These latter signals, together with that at high field, suggest the presence of a $\eta^{3}$-allyl ligand, as shown in the proposed structure of $\mathbf{1 2}$ (Scheme 5). In favor of this proposal, the ${ }^{1} \mathrm{H}$ NMR nOesy spectrum indicates the proximity of the $\mathrm{SiMe}$ and $\mathrm{SiMe}_{3}$ groups, while 
the ${ }^{1} \mathrm{H},{ }^{13} \mathrm{C}$ NMR hmbc correlation reveals long-range couplings between both of these groups and the $\mathrm{CH}_{2}$. Furthermore, other potential ways of combining a carbene and an alkyne in the coordination sphere of the metal ${ }^{35}$ can be discarded because they would lead to either highly unsaturated complexes or compounds containing both intact $\kappa-P, P, S i$ pincers and ligands with NMR-evident carbenoid quaternary carbons. Moreover, the most plausible pathway toward $\mathbf{1 2}$ from $\mathbf{3}$ and phenylacetylene is compatible with the literature results and the ease of the reaction. Assuming that, as shown in the previous pages, the alkyne coordination to ruthenium causes carbene insertion into the $\mathrm{Ru}-\mathrm{Si}$ bond, the formation of $\mathbf{1 2}$ would consist of a further insertion of the alkyne in the Ru-alkyl moiety ${ }^{36}$ followed by a 1,3 hydrogen shift transforming the resulting alkenyl ligand into an allyl. ${ }^{37}$

The second example of Scheme 5, the reaction between 3 and 3,3-dimethyl-1-buthyne to form complex 13, is much more elaborate than the previous one and, consistently, was observed to be much slower; taking several hours in dichloromethane solution at RT. Our monitoring of the transformation by NMR indicated that no intermediate accumulates up to concentrations allowing identification. The structure of $\mathbf{1 3}$ (Figure 7) meets several notable features. It contains a new pincer ligand with an alkenyl arm that coordinates $\eta^{2}$ forming a 1-ruthenacyclopropene. This type of alkenyl coordination has been previously observed in complexes of $\mathrm{Mo}, \mathrm{W}, \mathrm{Re}$ and $\mathrm{Os},{ }^{38}$ but not of $\mathrm{Ru}$, in spite of the fact that it has been proposed to rationalize the stereochemical outcome of several transformations catalyzed by complexes of this metal. ${ }^{39,40}$ One of such transformations is the anti addition of silanes to alkynes, in which the possible participation of $\eta^{2}$-alkenyl intermediates closely related to $\mathbf{1 3}$ has been discussed in depth. ${ }^{40}$ The bond distances within the ruthenacyclopropene ring are consistent with the expected presence of a $\mathrm{Ru}-\mathrm{C}$ double bond: ${ }^{38} \mathrm{Ru}-\mathrm{C}(31) 1.832(2)$, $\mathrm{Ru}-\mathrm{C}(30) 2.183(2)$ and $\mathrm{C}(30)-\mathrm{C}(31) 1.431(3) \AA$, and so are the ${ }^{13} \mathrm{C}\left\{{ }^{1} \mathrm{H}\right\}$ NMR signals corresponding to the alkenyl carbons: an apparent triplet at $\delta 330.45\left(J_{\mathrm{CP}}=5.9 \mathrm{~Hz}\right)$ and a singlet at $\delta 53.81$.

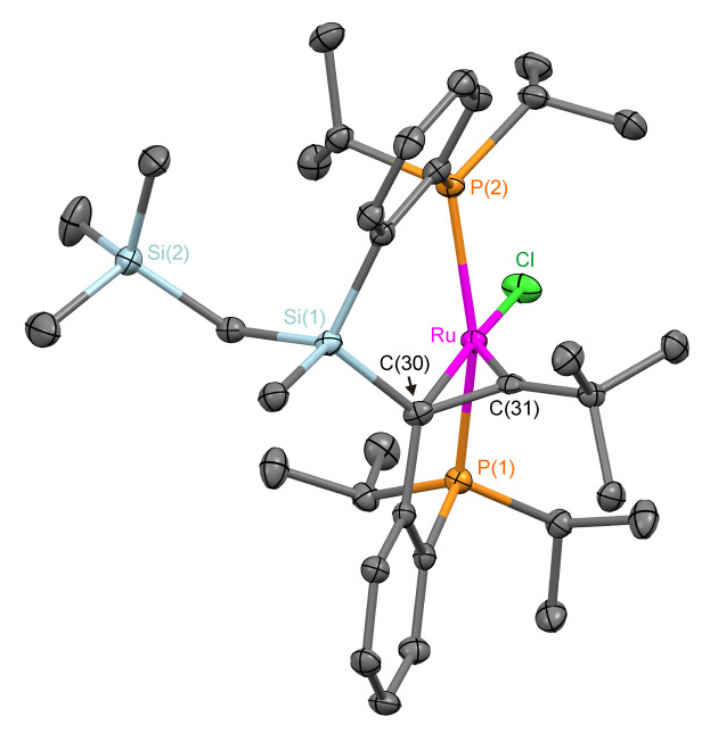

Figure 7. Crystal structure of complex 13 at 50\% probability level. The hydrogen atoms are omitted for clarity. For bond distances and angles see Supporting Information.
The structure of $\mathbf{1 3}$ again suggests a reaction pathway initiated by alkyne coordination and carbene insertion into the $\mathrm{Ru}-\mathrm{Si}$ bond, although the presence of the $\mathrm{CH}_{2} \mathrm{Si}(\mathrm{Me})_{3}$ substituent at the silicon of the former pincer seems to indicate that in this example the $\mathrm{C}-\mathrm{H}$ activation of the alkyne is preferred over its insertion into the $\mathrm{Ru}-\mathrm{C}$ bond. The formation of $\mathbf{1 3}$ also entails the very unusual insertion of a putative alkynyl ligand into a $\mathrm{Si}-\mathrm{C}$ bond: a process that is unlikely to occur directly even with the help of an unsaturated metal center. Instead, the process is likely to involve $\mathrm{Si}-\mathrm{C}$ bond cleavages and formations via oxidative additions and reductive eliminations, respectively, as such steps have been found to be facile in $\kappa-P, P, S i$ pincer complexes of $\mathrm{Ni}, \mathrm{Pd}, \mathrm{Rh}$ and $\mathrm{Ir}^{27,28,31}$ In any case, regardless the details of each structure, the reactions of Scheme 5 show that the inserted carbenes can indeed participate in reactions typical of alkyls such as migratory insertions or reductive eliminations.

\section{CONCLUSIONS}

The $\kappa-P, P, S i$ pincer ligand $\left[\mathrm{Si}(\mathrm{Me})\left(\mathrm{C}_{6} \mathrm{H}_{4}-2-\mathrm{PiPr}_{2}\right)_{2}\right]$ permits the preparation of five-coordinate ruthenium carbene complexes isoelectronic with the Grubbs catalyst but not isostructural, as they can offer a coordination site cis to the carbene ligand. The reactions with a variety of incoming ligands and other reagents indicate that the first response of these complexes to an increase of the coordination number around the metal is the insertion of the carbene ligand into the $\mathrm{Ru}-\mathrm{Si}$ bond. Such an insertion generates an alkyl moiety as well as a new coordination vacancy that enables further reactions. Since the insertion is reversible, these reactions can be those typical of carbene ligands, such as $\mathrm{C}-\mathrm{H}$ bond functionalizations or ketene formation from CO. Alternatively, they can be those characteristic of metal-bound alkyls, such as $\mathrm{C}-\mathrm{H}$ reductive eliminations or alkyne insertions. Ultimately, this capability of the pincer contributes to improve and diversify the reactivity of carbene ligands and therefore might constitute an exploitable ligand resource. Our current research efforts aim to recognize transformations that can benefit from this resource and to extend it to chemical entities other than carbenes.

\section{ASSOCIATED CONTENT}

\section{Supporting Information}

Experimental details for compound syntheses and characterization, and full crystallographic descriptions (CIF). This material is available free of charge via the Internet at http://pubs.acs.org.

\section{AUTHOR INFORMATION}

Corresponding Author

martam@unizar.es; sola@unizar.es

Notes

The authors declare no competing financial interest.

\section{ACKNOWLEDGMENT}

This research was supported by the Spanish MINECO (grants CTQ2009-08023 and CTQ2012-31774) and CSIC (PIE 201280E109).

\section{REFERENCES}

(1) (a) Hindson, K.; de Bruin, B. Eur. J. Inorg. Chem. 2012, 340. (b) Kaim, W. Inorg. Chem. 2011, 50, 9752.

(2) Grützmacher, H. Angew. Chem. Int. Ed. 2008, 47, 1814. 
(3) Crabtree, R. H. New. J. Chem. 2011, 35, 18.

(4) (a) Luca, O. R.; Crabtree, R. H. Chem. Soc. Rev. 2013, 42, 1440. (b) Lyaskovskyy, V.; de Bruin, B. ACS Catalysis 2012, 2, 270. (c) Dzik, W. I.; van der Vlugt, J. I.; Reek, J. N. H.; de Bruin, B. Angew. Chem. Int. Ed. 2011, 50, 3356. (d) Chirik, P. J.; Wieghardt, K. Science 2010, 327, 794.

(5) (a) Annibale, V. T.; Song, D. RSC Advances 2013, 3, 11432. (b) Askevold, B.; Roesky, H. W.; Schneider, S. ChemCatChem 2012, 4, 307. (c) Gunanathan, C.; Milstein, D. Acc. Chem. Res. 2011, 44, 588. (d) Ikariya, T. Bull. Chem. Soc. Jpn. 2011, 84, 1.

(6) For leading references of bifunctional ligands that exploit supramolecular interactions see ref. 3 and: (a) Dydio, P.; Detz, R. J.; Reek, J. N. H. J. Am. Chem. Soc. 2013, 135, 10817. (b) Fackler, P.; Huber, S. M.; Bach, T. J. Am. Chem. Soc. 2012, 134, 12869.

(7) (a) Kaim, W.; Schwederski, B. Coord. Chem. Rev. 2010, 254, 1580. (b) Buckel, W. Angew. Chem., Int. Ed. 2009, 48, 6779. (c) Stubbe, J.; Nocera, D. G.; Yee, C. S.; Chang, M. C. Y. Chem. Rev. 2003, 103, 2167. (d) Whittaker, J. W. Chem. Rev. 2003, 103, 2347. (e) Stubbe, J.; van der Donk, W. A. Chem. Rev. 1998, 98, 705.

(8) (a) Milstein, D. Top. Catal. 2010, 53, 915. (b) Ikariya, T.; Blacker, A. J. Acc. Chem. Res. 2007, 40, 1300. (c) Conley, B. L.; Pennington-Boggio, M. K.; Boz, E.; Williams, T. J. Chem. Rev. 2010, 110, 2294. (d) Käß, M.; Friedrich, A.; Drees, M.; Schneider, S. Angew. Chem. Int. Ed. 2009, 48, 905. (e) Noyori, R.; Yamakawa, M.; Hashiguchi, S. J. Org. Chem. 2001, 66, 7931. (f) Dang, Y.; Qu, S.; Wang, Z.-X.; Wang, X. Organometallics 2013, 32, 2804.

(9) (a) Kohl, S. W.; Weiner, L.; Schwartsburd, L.; Konstantinovski, L.; Shimon, L. J. W.; Ben-David, Y.; Iron, M. A., Milstein, D. Science 2009, 324, 74. (b) Hetterscheid, D. G. H.; van der Vlugt, J. I.; de Bruin, B.; Reek, J. N. H. Angew. Chem. Int. Ed. 2009, 48, 8178. (c) Ackermann, J. Chem. Rev. 2011, 111, 1315.

(10) Sola, E.; García-Camprubí, A.; Andrés, J. L.; Martín, M.; Plou, P. J. Am. Chem. Soc. 2010, 132, 9111.

(11) For recent work in silyl-pincer complexes and leading references: (a) Kirai, N.; Takaya, J.; Iwasawa, N. J. Am. Chem. Soc. 2013, 135, 2493. (b) Wu, S.; Li, X.; Xiong, Z.; Xu, W.; Lu, Y.; Sun, H. Organometallics 2013, 32, 3227. (c) Joost, M; Mallet-Ladeira, S.; Miqueu, K.; Amgoune, A.; Bourissou, D. Organometallics 2013, 32, 898. (d) Mitton, S. J.; Turculet, L. Chem. Eur. J. 2012, 18, 15258. (e) Fang, H.; Choe, Y.-K.; Li, Y.; Shimada, S. Chem. Asian J. 2011, 6, 2512. (f) Yang, J.; Del Rosal, I.; Fasulo, M.; Sangtrirutnugul, P.; Maron, L.; Tilley, T. D. Organometallics 2010, 29, 5544. (g) Zhou, X.; Stobart, S. R. Organometallics 2001, 20, 1898. See also: (h) Montiel-Palma, V.; Muñoz-Hernández, M. A.; Cuevas-Chávez, C. A.; Vendier, L.; Grellier, M.; Sabo-Etienne, S. Inorg. Chem. 2013, 52, 9798. (i) Brück, A.; Gallego, D.; Wang, W.; Irran, E.; Driess, M.; Hartwig, J. F. Angew. Chem. Int. Ed. 2012, 51, 11478.

(12) (a) Schwab, P.; Grubbs, R. H.; Ziller, J. W. J. Am. Chem. Soc. 1996, 118, 100. (b) Love, J. A.; Sanford, M. S.; Day, M. W.; Grubbs, R. H. J. Am. Chem. Soc. 2003, 125, 10103.

(13) For leading references on the mechanism of olefin metathesis: Ashworth, I. W.; Hillier, I. H.; Nelson, D. J.; Percy, J. M.; Vincent, M. A. ACS Catal. 2013, 3, 1929.

(14) MacInnis, M. C.; McDonald, R.; Ferguson, M. J.; Tobisch, S.; Turculet, L. J. Am. Chem. Soc. 2011, 133, 13622.

(15) (a) Katayama, H.; Yari, H.; Tanaka, M.: Ozawa, F. Chem. Commun. 2005, 4336. See also: (b) Lee, J.-H.; Cauton, K. G. J. Organometal. Chem. 2008, 693, 1664. (c) Bassetti, M.; Marini, S.; Gamasa, M. P.; RodríguezÁlvarez, García-Granda, S. Organometallics 2002, 21, 4815.

(16) Katayama, H.; Ozawa, F. Organometallics 1998, 17, 5190.

(17) Wolf, J.; Stuer, W.; Grunwald, C.; Gevert, O.; Laubender, M.; Werner, H. Eur.J. Inorg. Chem. 1998, 1827.

(18) Coe, B. J.; Glenwright, S. J. Coord. Chem. Rev. 2000, 203, 5.

(19) Yamaguchi, M.; Arikawa, Y.; Nishimura, Y.; Umakoshi, K.; Onishi, M. Chem. Commun. 2009, 2911.
(20) Ritter, T.; Hejl, A.; Wenzel, A. G.; Funk, T. W.; Grubbs, R. H. Organometallics 2006, 25, 5740 .

(21) (a) Allen, A. D.; Egle, I.; Janoschek, R.; Liu, H. W.; Ma, J.; Marra, R.; Tidwell, T. T. Chem. Lett. 1996, 45. (b) Valentí, E.; Pericás, M.A.; Serratosa, F. J. Org. Chem. 1990, 55, 395. (c) Black, T. H.; Farrell, J. R.; Probst, D. A.; Zotz, M. C. Synth. Commun. 2002, 32, 2083.

(22) For precedents of catalytic formation of ketenes: (a) Paul, N. D.; Chirila, A.; Lu, H.; Zhang, X. P.; de Bruin, B. Chem. Eur. J. 2013, 19, 12953. (b) Zhang, Z.; Liu, Y.; Ling, L.; Li, Y.; Dong, Y.; Gong, M.; Zhao, X.; Zhang, Y.; Wang, J. J. Am. Chem. Soc. 2011, 133, 4330.

(23) For leading references on metal-bound carbene insertions: Franssen, N. M. G.; Walters, A. J. C.; Reek, J. N. H.; de Bruin, B. Catal. Sci. Technol. 2011, 1, 153.

(24) For carbene migratory insertions in related complexes: (a) Burrell, A. K.; Clark, G. R.; Rickard, C. E. F.; Roper, W. R.; Wright, A. H. J. Chem. Soc., Dalton Trans. 1991, 609. See also: (b) Hill, A. F.; Roper, W. R.; Waters, J. M.; Wright, A. H. J. Am. Chem. Soc. 1983, 105, 5939. (c) Galan, B. R.; Pitak, M.; Gembicky, M.; Keister, J. B.; Diver, S. T. J. Am. Chem. Soc. 2009, 131, 6822.

(25) Latos-Grazynski, L.; Cheng, R.-J.; La Mar, G. N.; Balch, A. L. J. Am. Chem. Soc. 1981, 103, 4270.

(26) Whited, M. T.; Grubbs, R. H. Organometallics 2008, 27, 5737.

(27) (a) Mitton, S. J.; McDonald, R.; Turculet, L. Angew. Chem., Int. Ed. 2009 48, 8568. (b) Mitton, S. J.; McDonald, R.; Turculet, L. Polyhedron 2013, 52, 750. (c) Kameo, H.; Ishii, S.; Nakazawa, H. Dalton Trans. 2013 42,4663 .

(28) García-Camprubí, A.; Martín, M.; Sola, E. Inorg. Chem. 2010, 49, 10649

(29) Stobart, S. R.; Zhou, X.; Cea-Olivares, R; Toscazo, A. Organometallics 2001, 20, 4766.

(30) For leading references: (a) Montag, M.; Efremenko, I.; DiskinPosner,Y.; Ben-David, Y.; Martin, J. M. L.; Milstein, D. Organometallics 2012, 31, 505. See also: (b) Steinke, T.; Shaw, B. K.; Jong, H.; Patrick, B. O.; Fryzuk, M. D.; Green, J. C. J. Am. Chem. Soc. 2009, 131, 10461.

(31) (a) Takaya, J.; Iwasawa, N. Organometallics 2009, 28, 6636. (b) Takaya, J.; Iwasawa, N. J. Am. Chem. Soc. 2008, 130, 15254. See also: (c) North, M. Angew. Chem. Int. Ed. 2009, 48, 4104.

(32) Doyle, M. P.; Duffy, R.; Ratnikov, M.; Zhou, L. Chem. Rev. 2010, $110,704$.

(33) Díaz-Requejo, M. M.; Pérez, P. J. Chem. Rev. 2008, 108, 3379.

(34) Lo, V. K.-Y.; Guo, Z.; Choi, M. K.-W.; Yu, W.-Y.; Huang, J.-S.; Che, C.-M. J. Am. Chem. Soc. 2012, 134, 7588.

(35) (a) Trnka, T. M.; Day, M. W.; Grubbs, R. H. Organometallics 2001, 20, 3845. (b) O'Connor, J. M.; Baldridge, K. K.; Vélez, C. L.; Rheingold, A. L.; Moore, C. E. . J. Am. Chem. Soc. 2013, 135, 8826 and references therein. See also: (c) Le Paih, J.; Vovard-Le Bray, C.; Dérien, S.; Dixneuf, P. H. J. Am. Chem. Soc. 2010, 132, 7391.

(36) For leading references on alkyne insertions into $\mathrm{M}-\mathrm{C}$ bonds, see: Li, L.; Jiao, Y.; Brennessel, W. W.; Jones, W. D. Organometallics 2010, 29, 4593.

(37) For an example of 1,3 hydrogen migration, see: (a) MacDougall, T. J.; Samant, R. G.; Trepanier, S. J.; Ferguson, M. J.; McDonald, R.; Cowie, M. Organometallics 2012, 31, 1857. For related isomerizations of hydrocarbyl ligands leading to allyls, see: (b) Esteruelas, M. A.; Lahoz, F. J.; Oñate, E.; Oro, L. A.; Sola, E. J. Am. Chem. Soc. 1996, 118, 89.

(38) Frohnapfel, D. S.; Templeton, J. L. Coord. Chem. Rev. 2000, 206207, 199.

(39) Imazaki, Y.; Shirakawa, E.; Ueno, R.; Hayashi, T. J. Am. Chem. Soc. 2012, 134, 14760

(40) (a) Crabtree, R. H. New J. Chem. 2003, 27, 771. (b) Chung, L. W.; Wu, Y.-D.; Trost, B. M.; Ball, Z. T. J. Am. Chem. Soc. 2003, 125, 11578. 


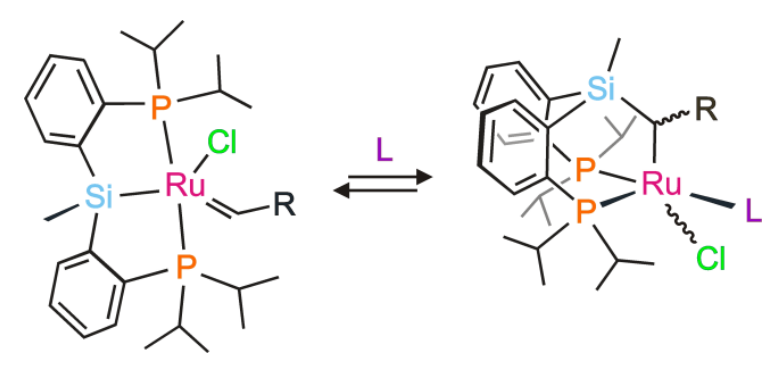

